\title{
Individual and community-level factors of perinatal mortality in the high mortality regions of Ethiopia: a multilevel mixed-effect analysis
}

Desalegn Girma ${ }^{1 *}\left(\mathbb{0}, Z_{\text {Zinie Abita }}{ }^{2}\right.$, Gossa Fetene ${ }^{1}$ and Bamlaku Birie ${ }^{1}$

\begin{abstract}
Background: Even though perinatal mortality has declined globally; it is still the major public health concern in sub-Saharan Africa countries. Ethiopia is one of the sub-Saharan countries which contribute the highest-burden of perinatal mortality with a devastating rate in some of the regions. Therefore, this study aimed to identify the determinants of perinatal mortality in the high mortality regions of Ethiopia.

Method: A secondary data analysis was done using the 2016 Ethiopian Demographic and Health Survey data. The outcomes of 4120 pregnancies reaching $\geq 7$ months of gestational age were considered for the analysis. A multilevel mixed logistic regression model was fitted to identify the predictors of perinatal mortality. Finally, a statistically significant association was declared at a $p$-value of $\leq 0.05$.

Result: The study found that birth interval $<2$ years ( $\mathrm{AOR}=3.71,95 \% \mathrm{Cl}: 2.27,6.07)$, having no antenatal care $(A O R=2.43,95 \% \mathrm{Cl}: 1.15,5.38)$, initiating breastfeeding after $1 \mathrm{~h}(\mathrm{AOR}=4.01,95 \% \mathrm{Cl}: 2.49,6.51)$, being distant from health institutions ( $A O R=1.99,95 \% \mathrm{Cl}: 1.24,3.22)$, having previous terminated pregnancy $(\mathrm{AOR}=4.68,95 \% \mathrm{Cl}: 2.76,7.86)$, being mothers not autonomous $(\mathrm{AOR}=1.96,95 \% \mathrm{Cl}: 1.19,3.20)$,being no media exposure ( $\mathrm{AOR}=2.78,95 \% \mathrm{Cl}: 1.48,5.59)$, being households $\leq 4$ family sizes ( $A O R=4.12,95 \% \mathrm{Cl}: 2.19,7.79)$, having $\geq 6$ parity ( $\mathrm{AOR}=2.48,95 \% \mathrm{Cl}: 1.21,5.22)$ were associated with a high odds of perinatal mortality.

Conclusion: The study concludes that birth interval, antenatal care, time for breastfeeding initiation, distance from health institutions, previous history of terminated pregnancy, maternal autonomy, media exposure, family size, and parity were predictors of prenatal mortality. Therefore, programmatic emphases to maternal waiting service utilization for mothers distant from health institutions and media advertising regarding the complications related to pregnancy, childbirth and on its respective direction that the mothers should follow could reduce perinatal mortality in high mortality regions of Ethiopia.
\end{abstract}

Keywords: Ethiopia, Perinatal mortality, Regions, Multilevel analysis

${ }^{*}$ Correspondence: desegir@gmail.com

${ }^{1}$ Department of Midwifery, College of Health Science, Mizan-Tepi University, Mizan, Ethiopia

Full list of author information is available at the end of the article

\section{Background}

Perinatal mortality includes both terminated pregnancies after seven months (stillbirth) and early neonatal deaths in the first week of life [1]. It is an important indicator of the quality of maternal and neonatal care in the country [2]. 
Perinatal mortality is one of the public health concerns; globally, nearly 2 million annual stillbirths [3] and about 2.4 million newborn death [4] have been reported in 2019, with the highest-burden in low-income centuries. The risk of stillbirth is 7.6 times higher in low-income countries whereas the risk of newborn death is 9 times higher as compared to the high-income countries $[3,5]$.

Even though there is a global decline in stillbirth from 2.9 million in 2000 to 2.0 million in 2019 [3] and neonatal deaths from 5.0 million in 1990 to 2.4 million in 2019 [4], the perinatal mortality rate is still high in sub-subSaharan Africa countries which ranges from 34.7 to 42.95 per 1000 live births $[6,7]$. It covers about 42 percent of the total stillbirth [3] and 41 percent of the total newborn death [5] of the globe.

The world has launched a platform "Every Newborn Action Plan (ENAP)" in 2014 to decline stillbirths and neonatal deaths to less than 10 per1,000 total births of countries by 2035 [8]. However, neonatal death and stillbirth have been reduced stagnantly in low-income countries and such countries need to accelerate the reductions of deaths to achieve the proposed targets [9].

Ethiopia is one of the developing countries in subSaharan Africa that have the highest fertility rate (to 4.6 children per woman) with a median age of first birth at 19.2 years [10] and has a low physician density (0. 0769 per 1,000 people) [11].

Ethiopia has been working by endorsing "Every Newborn Action Plan" to reduce the rate of perinatal mortality though it is still one of the major public health concerns in Ethiopia. In 2016, the Ethiopian Demographic and Health Survey (EDHS) reported about 33 perinatal death per 1000 birth [10]. A systematic review conducted in Ethiopia also revealed a high perinatal death (51.3 per 1000 birth) in the year between 1997 to 2019 [12]. The overall mortality rate has variation among regions and it was devastating in some of the regions in Ethiopia. According to the 2016 Ethiopian Demographic and Health Survey (EDHS) report, perinatal mortality per 1000 live births was higher in Somali, Amhara, Harari, and Tigray regions( 50, 44, 40, and 36, respectively) as compared to the national average(33 death per 1000 live birth) [10].

Perinatal mortality is known to be associated with factors such as paritry [13-15], age of mother [13, 16], maternal education [17, 18], Attending antenatal care visits(ANC) [14-16, 19], skilled birth attendant [14], previous history of perinatal mortality $[14,16,20]$, low family income, birth interval $[12,19,20]$, the total number of under 5 children [20], access to participation in decision making [20], conceived during teenage [21], and place of delivery [22, 23] and residency [15], and access to clean water supply [1].
Even though Ethiopia has been working to decline perinatal mortality, by ensuring equity in health, maximizing the coverage of health facilities, and improving the quality care of maternal and child health, perinatal mortality is still very high in some regions of Ethiopia (Somali, Amhara, Harari, and Tigray) [24]. Previous studies [14, 15, 22, 25-27] conducted in Ethiopia on perinatal mortality have tried to identify individuallevel determinants of perinatal mortality in specific areas. However, they didn't assess community-level factors that may influence perinatal mortality in high prevalence regions. Therefore, the primary aim of this study was to identify the individual and community level determinant factors of perinatal mortality in these high perinatal mortality regions of Ethiopia by using nationally representative data. Identifying the individual and community level factors is significant to reduce perinatal mortality in high mortality regions of Ethiopia.

\section{Methods}

\section{Data source}

The Ethiopian Demographic and Health Survey (EDHS 2016) data were used, which was the fourth survey conducted nationally from January 18 to June 27, 2016. The respondents in EDHS, 2016 were selected by using a two-stage stratified sampling technique. In the first stage, 645 enumeration areas (202 in urban areas and 443 in rural areas) were selected. Then in the second stage, 28 households per cluster have been selected. The detailed sampling technique was summarized in the full EDHS 2016 report [10]. A total of 4014 mothers from the high perinatal mortality regions(Somali, Amhara, Harari, and Tigray) were included in the study. Accordingly, the outcomes of 4120 pregnancies reaching $\geq 7$ months of gestational age(including twin pregnancies) were analyzed to identify factors affecting perinatal mortality. Most of the variables related to pregnancy and postnatal care in EDHS data were only collected for the last birth or last pregnancy. Such that for women who had two or more pregnancies in the 5 years preceding the survey, the last pregnancy was taken. About $11.73 \%$ of the pregnancies were excluded from the study. Those have incomplete data mainly the gestational age, birth dates, and ages at deaths. The comparison of perinatal death between the Analytic sample and missing sample was checked using the chi-square test. The result revealed that there is no significant difference in perinatal death between the Analytic sample group and missing sample (3.9\% vs $\left.4.4 \%, \mathrm{x}^{2}=0.414, \mathrm{P}=0.255\right)$ with perinatal mortality rate 41 per 1000 vs 44 per 1000 live birth, respectively (Appendix). 


\section{Variables of the study Dependent variable}

The perinatal mortality rate was a dependent variable, including both stillbirths and early neonatal deaths in the five years preceding the survey divided by all births (including stillbirths) that have a pregnancy duration of seven or more months. Stillbirth is defined as pregnancy terminated after seven or more months. Early neonatal death is death within seven days (days $0-6)$. The outcome variables were coded as "0" for the absence of perinatal mortality and " 1 " for the presence of perinatal mortality.

\section{Independent variables}

Predictors such as maternal age (years), maternal education status, paternal education status, Sex of household, working status of mothers, family size, wealth index, media exposure, age at first birth, place of delivery, preceding birth interval, women participating in making health care decisions, parity, time to breastfeeding Initiations, postnatal care, previous history of a terminated pregnancy, antenatal visit, tetanus toxoid vaccination, and Health insurance were considered as individual-level factors. And factors such as residence, distance from health facilities, water facility, and times to reach the water source were considered as community-level factors.

For the media exposure the composite variable is created from three variables; frequency of watching $\mathrm{TV}$, reading a newspaper, and listening to the radio, and coded as "yes" if an individual was exposed to all or either of the three and "No" if an individual was not exposed to at least one of these. The women's health care decision-making autonomy was assessed as the person who usually decides to obtain healthcare. Which was categorized as women participating in making health care decisions and didn't participate in making health care decisions (decided by their husband/ partner).

The water source was leveled as improved if the source of drinking water comprises one of the following: a piped household connection, public standpipe/borehole, protected dug well or spring, and/or rainwater collection. The toilet facility was leveled as improved if it has (piped into dwelling, piped to yard/plot, piped to a neighbor, and public tap/standpipe) and not improved for (no facility/bush/field, composting toilet). wealth index, In the original it was categorized into five wealth quintiles: 'very poor,' 'poor', 'middle', 'rich', and 'very rich'. For this study, we re-coded the wealth index into three categories as 'poor' (poor and very poor), 'middle', and 'rich' (rich and very rich) to obtain an adequate sample in each category.

\section{Statistical analysis}

Data were extracted using SPSS version 21 software and then exported to $\mathrm{R}$ version 3.5.3 statistical software for further analysis. Data editing, coding, and cleaning were done. Frequencies, percentages, and the rate were used to summarize data, and tables were used to present data. In this study, a two levels hierarchy of data was considered due to the sampling techniques used in the EDHS (multi-stage stratified cluster) data. Level one units were individual pregnant mothers in households and level two units were enumeration areas (cluster). Level one (pregnant mothers in the households) was nested at the next higher level of enumeration areas (community). Therefore, the multilevel mixed logistic regression model was fitted to identify the contributing factors of perinatal mortality at each level (individual level and community level). Both bivariable and multivariable analyses were conducted. Variables that have a $P$-value of $\leq 0.25$ in bivariable two-level binary logistic regression were a candidate for multivariable multilevel logistic regression analysis. Then Variables in multilevel multivariable logistic regression were declared to be statistically significant at a $P$-value of $\leq 0.05$.

Four models have been developed, With an assumption of varying intercepts across communities (clusters) but fixed coefficients. The first was the null model (Model I) fitted without predictors variables. The second model (model II) was fitted for individual-level factors and conducted to examine the contribution to the variation of perinatal mortality. Whereas the third model (Model III) was adjusted for community-level factors and used to examine the contribution for variation of perinatal mortality across the cluster. Finally, the fourth model(Model IV) was developed by combining individual and community level factors. The model goodness of fit was tested using deviance information criteria (DIC)and the model with the lowest value was considered to be the best fit model. The variation inflation factor (VIF) was used to test the multicollinearity between independent variables.

\section{Results}

Socio-demographic characteristics and perinatal mortality rates

Out of 3322 (weighted) pregnancies, about 2806(84.5\%) were from rural mothers and 2362(71.1\%) were from mothers with no formal education. The overall perinatal mortality rate among the pregnancy in high mortality regions of Ethiopia was 41 per1000 births. The perinatal mortality rate was high among mothers aged $\geq 35$ years (58.57 per 1000 ), households $\leq 4$ family size (53.66 per 1000), households who had Poor wealth index (55.42 
Table 1 Shows that the perinatal mortality among pregnancy by socio-demographic characteristics in high mortality regions, Ethiopia, 2016

\begin{tabular}{|c|c|c|c|c|c|}
\hline Variable & Categories & Frequency (\%) & $\begin{array}{l}\text { weighted } \\
\text { Frequency } \\
\text { (\%) }\end{array}$ & $\begin{array}{l}\text { unweighted number of } \\
\text { perinatal deaths (PMR [per } \\
1,000] \text { ) }\end{array}$ & $\begin{array}{l}\text { weighted number of } \\
\text { perinatal deaths (PMR [per } \\
1,000] \text { ) }\end{array}$ \\
\hline \multirow[t]{5}{*}{ Maternal age (years) } & Less 20 & $151(3.7)$ & $99(3)$ & $8(57.14)$ & $4(43.01)$ \\
\hline & $20-24$ & $862(20.9)$ & $606(18.2)$ & $33(40.69)$ & $12(20.90)$ \\
\hline & $25-29$ & $1135(27.5)$ & $957(28.8)$ & $54(49.82)$ & $40(43.80)$ \\
\hline & $30-34$ & $858(20.8)$ & $664(20)$ & $26(31.82)$ & $19(29.60)$ \\
\hline & $\geq 35$ & $1114(27.0)$ & $996(30)$ & $61(58.59)$ & $55(58.57)$ \\
\hline \multirow[t]{2}{*}{ Residence } & Urban & $760(18.4)$ & $516(15.5)$ & $19(25.8)$ & 15(30.00) \\
\hline & Rural & $3360(81.6)$ & $2806(84.5)$ & 163(51.6) & $115(43.23)$ \\
\hline \multirow[t]{3}{*}{ Maternal education status } & No education & 2892(70.2) & $2362(71.1)$ & 134(49.24) & 105(47.06) \\
\hline & Primary & $872(21.2)$ & $700(21.1)$ & $36(43.53)$ & $21(31.00)$ \\
\hline & Secondary and above & $356(8.6)$ & $260(7.8)$ & $12(34.78)$ & $4(16.00)$ \\
\hline \multirow[t]{2}{*}{ Sex of house hold } & Male & $3288(79.8)$ & $2841(85.5)$ & 153(49.27) & 107(39.54) \\
\hline & Female & $832(20.2)$ & $481(14.5)$ & $29(36.80)$ & $23(50.77)$ \\
\hline \multirow[t]{3}{*}{ Paternal education status } & No education & $2257(54.8)$ & $2027(61.0)$ & $111(52.38)$ & $91(47.42)$ \\
\hline & Primary & $1041(25.3)$ & $767(23.1)$ & $38(38.38)$ & $23(31.50)$ \\
\hline & Secondary and above & $545(13.2)$ & $324(9.7)$ & $23(43.80)$ & $8(25.20)$ \\
\hline \multirow[t]{2}{*}{ Mother Currently working } & Yes & $936(22.7)$ & $738(22.2)$ & $42(47.79)$ & $29(41.25)$ \\
\hline & No & $3184(77.3)$ & 2584(77.8) & $140(46.45)$ & $101(41.12)$ \\
\hline \multirow[t]{2}{*}{ Family size } & $>4$ & 2954(71.7) & $2280(68.6)$ & 108(38.37) & $78(35.62)$ \\
\hline & $\leq 4$ & $1166(28.3)$ & $1042(31.4)$ & $74(68.64)$ & $52(53.66)$ \\
\hline \multirow[t]{3}{*}{ Wealth index } & Rich & 1013(24.6) & $953(28.7)$ & $20(20.47)$ & $21(22.70)$ \\
\hline & Medium & $665(16.1)$ & $665(20.0)$ & $22(34.59)$ & $20(31.84)$ \\
\hline & Poor & $2442(59.3)$ & 1704(51.3) & $140(61.40)$ & $89(55.42)$ \\
\hline \multirow[t]{2}{*}{ Media exposure } & Yes & $1441(35.0)$ & $1114(33.5)$ & $24(17.30)$ & $24(22.39)$ \\
\hline & No & $2679(65.0)$ & $2208(66.5)$ & 158(63.05) & 106(50.79) \\
\hline \multirow[t]{2}{*}{ Improved water source } & Yes & $2253(54.7)$ & 1814(54.6) & $88(40.93)$ & $72(41.43)$ \\
\hline & No & $1867(45.3)$ & $1508(45.4)$ & $94(53.93)$ & $58(41.00)$ \\
\hline \multirow[t]{2}{*}{ Improved toilet facility } & Yes & $2281(55.4)$ & $1807(54.4)$ & 103(47.91) & 68(39.72) \\
\hline & No & 1839(44.6) & 1515(45.6) & $79(45.32)$ & $62(42.84)$ \\
\hline \multirow[t]{2}{*}{ Times to reach water source } & $<30 \min$ & $1686(40.9)$ & 1583(47.6) & $67(42.00)$ & $59(38.74)$ \\
\hline & $\geq 30 \mathrm{~min}$ & $2434(59.1)$ & $1739(52.4)$ & $115(50.00)$ & $71(43.39)$ \\
\hline
\end{tabular}

Variables measured at the time of the survey: residence, education status, wealth index, sex of household, working status, family size, media exposure, water source, and toilet facility

Variables measured at the time of birth: maternal age (years)

PMR perinatal mortality rate

per 1000), and mothers who didn't have media exposure (50.79 per 1000) (Table 1$)$.

\section{Reproductive characteristics and perinatal mortality rates} Out of the total 3322 (weighted) pregnancies, about 1604(48.3\%) of pregnancies were to women who first gave birth when they were $<18$ years. The Perinatal mortality among pregnancies was higher in mothers who have a previous history of terminated pregnancy (126.40 per 1000), mothers who have home delivery (52.00 per 1000), mothers who didn't have participation in making health care decisions (45.38 per 1000$)$, mothers who have a birth interval of $<2$ years (99.12 per 1000), mothers who had $\geq 6$ parity (86.62 per 1000), mothers who didn't have ANC follow up (57.78 per 1000), and mothers who have a big problem of distance from the health facility (75.77 per 1000) (Table 2).

\section{Model comparison}

The Multicollinearity of the independent variables was checked by using the variation inflation factor (VIF). The VIF was found to range from 1.1 to 1.5 with a mean VIF of 1 . 2. This shows that multicollinearity might not be a problem. The DIC values for each model were compared 
Table 2 Show that the perinatal mortality among pregnancy by reproductive health characteristics of study participants in high mortality regions, Ethiopia, 2016

\begin{tabular}{|c|c|c|c|c|c|}
\hline Variable & Categories & Frequency (\%) & $\begin{array}{l}\text { weighted } \\
\text { Frequency } \\
\text { (\%) }\end{array}$ & $\begin{array}{l}\text { unweighted Number of } \\
\text { perinatal deaths (PMR [per } \\
1,000] \text { ) }\end{array}$ & $\begin{array}{l}\text { weighted number of } \\
\text { perinatal deaths (PMR [per } \\
1,000] \text { ) }\end{array}$ \\
\hline \multirow[t]{2}{*}{ Age at first birth } & $<18$ years & 2002(48.6) & $1604(48.3)$ & $95(50.29)$ & $76(46.62)$ \\
\hline & $\geq 18$ years & $2118(51.4)$ & $1718(51.7)$ & $87(43.41)$ & $54(35.32)$ \\
\hline \multirow[t]{2}{*}{ Place of delivery } & Health institution & 1853(45.0) & $1453(43.7)$ & $53(29.79)$ & $38(27.35)$ \\
\hline & Home & $2267(55.0)$ & 1869(56.3) & $129(61.02)$ & $92(52.00)$ \\
\hline \multirow[t]{2}{*}{ Preceding birth interval (N:2684) } & $\geq 2$ years & $2404(72.1)$ & 2183(81.3) & $68(29.42)$ & 65(30.98) \\
\hline & $<2$ years & $929(27.9)$ & $501(18.7)$ & $75(88.86)$ & 45(99.12) \\
\hline \multirow{2}{*}{$\begin{array}{l}\text { Women participating in making } \\
\text { health care decisions }\end{array}$} & Yes & $3146(76.4)$ & $2881(86.7)$ & 101(33.73) & $100(40.00)$ \\
\hline & No & $974(23.6)$ & $441(13.3)$ & $81(91.11)$ & $30(45.38)$ \\
\hline \multirow[t]{3}{*}{ Parity } & $1-3$ & $1778(43.2)$ & 1533(46.1) & $70(41.20)$ & $42(28.59)$ \\
\hline & $4-6$ & 1435(34.8) & 1076(32.4) & $59(43.51)$ & $31(30.03)$ \\
\hline & $\geq 6$ & $907(22.0)$ & $713(21.5)$ & $53(63.25)$ & $57(86.62)$ \\
\hline \multirow[t]{2}{*}{ Time to breastfeeding Initiations } & Within1hour & 1933(46.9) & $1637(49.3)$ & $43(22.76)$ & $29(18.57)$ \\
\hline & $>1 \mathrm{~h}$ & $2187(53.1)$ & $1685(50.7)$ & 139(69.36) & $101(65.04)$ \\
\hline \multirow[t]{2}{*}{ Postnatal care with 2 days } & Yes & 2618(63.5) & 1957(58.9) & 107(43.39) & $68(36.67)$ \\
\hline & No & $1502(36.5)$ & $1365(41.1)$ & $75(52.56)$ & $62(47.54)$ \\
\hline \multirow[t]{2}{*}{ Ever had a terminated pregnancy } & No & $3660(88.8)$ & 2949(88.8) & $129(37.34)$ & $85(30.32)$ \\
\hline & Yes & $460(11.2)$ & $373(11.2)$ & $53(120.72)$ & $45(126.40)$ \\
\hline \multirow[t]{3}{*}{ Antenatal care visits (N:2456) } & $\geq 4$ visits & $952(34.6)$ & $892(36.3)$ & $23(24.46)$ & $25(28.67)$ \\
\hline & $1-3$ visits & 934(33.9) & $850(34.6)$ & $22(24.10)$ & 20(24.09) \\
\hline & No at all & $868(31.5)$ & $714(29.1)$ & $64(79.11)$ & $39(57.78)$ \\
\hline \multirow[t]{3}{*}{ Tetanus toxoid vaccination } & Not all & $1241(45.1)$ & $1107(45.1)$ & $64(54.10)$ & 43(40.49) \\
\hline & One times & $371(13.5)$ & $386(15.7)$ & $7(19.61)$ & 14(37.83) \\
\hline & $\geq 2+$ & $1141(41.4)$ & $962(39.2)$ & $37(33.21)$ & $26(27.51)$ \\
\hline \multirow[t]{2}{*}{ Distance from Health facilities } & Not big problem & 2819(68.4) & $2315(69.7)$ & $79(29.32)$ & $59(26.55)$ \\
\hline & Big problem & $1301(31.6)$ & 1007(30.3) & 103(85.90) & $71(75.770$ \\
\hline \multirow[t]{2}{*}{ Health insurance } & Yes & $3884(94.3)$ & 3018(90.8) & $8(34.33)$ & $12(40.00))$ \\
\hline & No & $236(5.7)$ & $304(9.2)$ & $174(47.54)$ & $118(41.22)$ \\
\hline
\end{tabular}

Variables measured at the time of birth: age at first birth, place of delivery, birth interval, parity, time to breastfeeding initiations, postnatal care, antenatal care visits, tetanus toxoid vaccination, and history of terminated pregnancy

Variables measured at the time of the survey: distance from health facilities, health insurance, and women participation in making health care decisions PMR perinatal mortality rate

(i.e. model I:1484.8, model II:568.6, model III: 1474.9, and model IV: 566.6$)$ and the model with the lowest value of DIC was selected as a better explanatory model. Based on this, model four with a DIC value (566.6) was selected as the best-fitted model to explain perinatal mortality in high mortality regions of Ethiopia.

\section{Factors associated with perinatal mortality}

In the bivariable multilevel logistic regression analysis, variables like maternal age (years), maternal education status, paternal education status, Sex of household, working status of mothers, age at first birth, health insurance, water facility, and toilet facility had p-value $>0.25$ and they were not eligible for multivariable multilevel analysis. In multivariable multilevel analysis, birth interval, media exposure, ANC follow up, time to breastfeeding initiation, maternal parity, previous history of terminated pregnancy, family size, women participation in making health care decisions, and distance from a health facility was significantly associated with perinatal mortality at P-value of $\leq 0.05$. Based on this, The odds of perinatal mortality were 3.71 times higher $(\mathrm{AOR}=3.71$, 95\%CI: $2.27,6.07$ ) among mothers who have $<2$ years' birth interval as compared to mothers who have $\geq 2$ years birth interval. The odds of perinatal mortality were 2.43 times higher $(\mathrm{AOR}=2.43,95 \% \mathrm{CI}: 1.15,5.38)$ among mothers who didn't have ANC visits as compared to mothers who have $\geq 4$ visits. The odd of perinatal 
mortality were 4.01 times higher $(\mathrm{AOR}=4.01,95 \% \mathrm{CI}$ : $2.49,6.51$ ) among mothers who didn't start breastfeeding within one hour of birth as compared to mothers who starts within the first one hour. The odd of perinatal mortality were nearly two times higher $(\mathrm{AOR}=1.99,95 \% \mathrm{CI}$ : $1.24,3.22$ ) among mothers who are far from health institutions as compared to their counterparts. The odd of perinatal mortality was 4.68 times higher $(\mathrm{AOR}=4.68$, $95 \%$ CI: $2.76,7.86$ ) among mothers who have a previous history of terminated pregnancy as compared to mothers who didn't have a previous history of terminated pregnancy. The odd of perinatal mortality were nearly two times higher (AOR $=1.96,95 \% \mathrm{CI}: 1.19,3.20)$ among mothers who didn't have autonomy in making health care decisions as compared to their counterparts. The odd of perinatal mortality among mothers who didn't have media exposure was 2.78 times higher $(\mathrm{AOR}=2.78$, $95 \% \mathrm{CI}: 1.48,5.59)$ as compared to mothers who have media exposure. Being Households $\leq 4$ family sizes were associated with a higher odds of perinatal mortality $(\mathrm{AOR}=4.12,95 \% \mathrm{CI}: 2.19,7.79)$ as compared to households with greater than four family sizes. The odd of perinatal mortality among mothers who have $\geq 6$ parity were 2.48 times higher $(\mathrm{AOR}=2.48,95 \% \mathrm{CI}: 1.21,5.22)$ as compared to mothers who have one to three parity (Table 3 ).

\section{Discussion}

The study aimed to identify the individual and community-level factors of perinatal mortality in high mortality regions of Ethiopia. Our study found that birth interval, media exposure, ANC follow up, time to breastfeeding initiation, maternal parity, previous history of terminated pregnancy, family size, women participation health care decisions and distance from a health facility were significant predictors of perinatal mortality.

The study revealed that mothers who gave birth in less than 2-year intervals have higher odds of perinatal mortality as compared to those who gave birth after 2-year intervals. The finding is supported by other studies [12, $19,20,25,26,28]$. The possible explanation may be due to that short birth intervals hurt the nutritional recovery, healing of the endometrium, cervical competency, and the optimal lactation of the breast which determines the outcomes of the subsequent pregnancy [29]. Thus, measures should be taken to promote family planning utilization to space the succeeding pregnancy.

The odds of perinatal mortality were higher among mothers who didn't have antenatal care visits as compared to mothers who have four and above antenatal care visits. The finding is supported by other studies [7, 1416, 19]. The possible justification might be that having more antenatal care visits was an opportunity for health professionals to give health education, identify pregnancy with complications, and treat an existing disease [30]. In addition, having a quality antenatal care service will facilitate mothers to deliver in a health institution, and increase mothers' knowledge regarding the care that has been given in health institutions such as essential newborn care [31].

The study revealed that the mothers who have no autonomy in making health care decisions are more likely to have higher odds of perinatal mortality as compared to their counterparts. This is in agreement with the study conducted in Bangladesh [20]. The possible explanation may be due to those women who are autonomous in making health care decisions were more likely to have antenatal follow up [32-34], postnatal care [32, 34], and delivered at the health facility $[33,34]$. It is crucial to identify and treat an existing complication in pregnancy and early in the newborn baby.

Unlike the study done in Bangladesh [20], in this study, mothers who have no media exposure have higher odds of perinatal mortality as compared to their counterparts. The possible justifications for such findings may be due to that those mothers who have exposure to media are in advantage of getting information regarding preventive measures of perinatal mortality such as maternal and child health services utilization. In addition, they might have information on complications related to pregnancy and childbirth which urges the mother for seeking early health care.

In agreement with studies [14, 25], this study found that mothers who have a previous history of terminated pregnancy are associated with a high odds of perinatal mortality as compared to their counterparts. This might be due that the genetic make-up of mothers and repeated exposure to environmental factors or this might be due to the problems related to the reproductive organs such as the uterus, and cervix or it may be due to problems related to the anatomical structure of the pelvic floor. In addition to this, it can be explained as the cultural impact in the community may force the couples to replace the lost fetus or newborn within a short birth interval without full recovery of mothers; this will determine the outcomes of pregnancy. Thus, mothers should be linked to reproductive health services and counseled on birth intervals. In addition, special investigation and care should be considered in the subsequent pregnancy.

Late initiation of breastfeeding (after one hour) is another factor that shows high odds of perinatal mortality (early newborn). The finding is supported by the study conducted in India [35]. The possible reason might be that timely initiation of breastfeeding is an assurance that a newborn has received colostrum; which contains infection protecting antibodies and reduces early newborn mortality resulting from infectious diseases. Thus, 
Table 3 Shows the multivariable multilevel analysis of factors associated with perinatal mortality in high mortality regions, Ethiopia, 2016

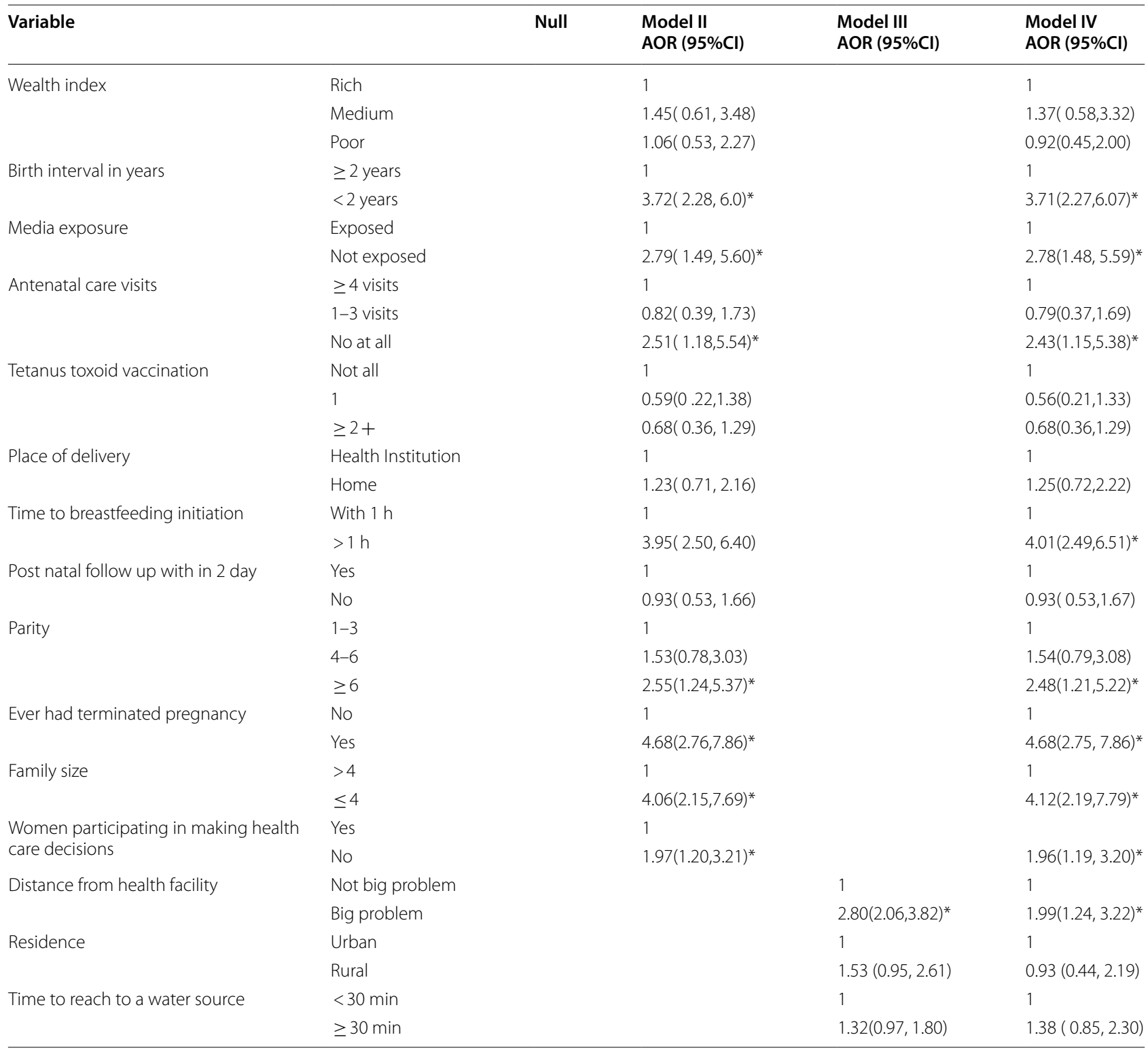

1: Reference OR Adjusted Odds Ratio, CI Confidence Interval

${ }^{*}=P \leq 0.05$

measures such as health education in every birth are needed to initiate breastfeeding within one hour of birth.

Unlink to the other study [36], this study found that being far from the health institutions is significantly associated with higher odds of perinatal mortality. The proximity to a health institution will reduce the burden of transportation and help the mother have antenatal care and institutional delivery, which was an important opportunity to screen and treat an existing disease in early newborn and pregnant mothers. This has a programmatic implication that the maternal waiting service should be strengthened and special consideration should be given to pregnant mothers thus far from health institutions.

Being Households $\leq 4$ family sizes were associated with higher odds of perinatal mortality as compared to households who had greater than four family sizes. The finding is supported by a study in West Gojam zone [22]. The possible explanation might be that the large family members will reduce the workload of pregnant mothers 
in homes and give enough time for resting and attending hospital follow-up care such as antenatal and postnatal care. Such care will have an advantage on the outcomes of the pregnancy.

The odd of perinatal mortality is higher among mother who has six parity compared to mothers who have one to three parity. The finding is in agreement with the study conducted in Sekota [15] and contrary to the study has done in Jimma [14]. This may be due to the reason that the repeated pregnancy in grand multipara mothers may lead to fetal nutritional deprivation which can cause either stillbirth or early neonatal death. Thus, grand Para mothers should be seen in special during antenatal care visits.

In the Previous study, lower socioeconomic status was reported as contributing factor of adverse pregnancy outcomes [37], on the contrary, this study revealed that the wealth index was not independently associated with perinatal mortality after controlling for other individuals and community-level characteristics. This might be due to the free provision of the preventive measure of perinatal mortality such as maternal and child health services in Ethiopia to all mothers irrespective of their economic status.

Whereas prior studies have linked maternal education status to perinatal mortality $[17,18]$, our findings are similar to previous studies in Ethiopia [14, 15, 19, 22, $23,26,27$ found no association between perinatal death and maternal education status. The possible justification might be due to the home-to-home service of health extension workers in Ethiopia to all mothers regardless of the educational status, such as the provision of health education, screening mothers with obstetrics complications, and early referring including newborns with complications.

The clinical and public health implication of this study is to take prompt intervention on the determinant factors and response to halt the high burden of perinatal mortality. Therefore, considering and taking special attention to birth spacing, antenatal care utilization, time to breastfeeding initiation of a newborn, the mothers who are distant from health institutions, the mothers have a previous history of a terminated pregnancy, empowering mother participation in making health care decision, mothers have no exposure to media, mothers from large household size and the Grand Para mothers could reduce perinatal mortality in high mortality regions of Ethiopia.

\section{Strength and limitation}

The study has used nationality representative data of 2016 EDHS and which is considered to have good generalizability. Besides, we have employed an appropriate statistical approach (multilevel mixed analysis) to estimate the cluster effect on perinatal mortality. However, the study shares the limitation of a cross-sectional study that was impossible to establish the cause and effect relationship. This study might have a recall bias, particularly for variables such as age, preceding birth interval, parity, time to breastfeeding initiation, postnatal care, and antenatal care visits or other retrospective data relying on memory of past events. Inaccurate reporting of respondents on crucial variables (gestational age, birth dates, and ages at death) used for estimating perinatal mortality, may result in underestimation or overestimation of perinatal mortality. The study is not considered the recommended birth weight of fetuses $(\geq 1000 \mathrm{gm}$ ) to estimate the stillbirth of perinatal mortality, hence, we only used the gestational age of fetuses; fetuses blew this weight may be incorporated in the study and may lead to overestimation of the mortality. This study has only analyzed the outcomes of the last pregnancy. Thus, the pregnancies to women with higher parity and shorter birth intervals might be excluded. This might lower the perinatal mortality and have an impact on the association of parity, birth intervals with perinatal mortality. The other limitation of this study is raised from the missing data that the pooled result of the perinatal mortality rate was lowered due to the pregnancies that had higher perinatal mortality being excluded from the analysis.

\section{Conclusion}

The study concludes that birth interval, antenatal care, time to breastfeeding initiation, distance from health institutions and previous history of a terminated pregnancy, maternal autonomy, media exposure, family size, and parity were predictors of prenatal mortality. Therefore, programmatic emphases to maternal waiting service utilization for mothers distant from health institutions and media advertising regarding the complications related to pregnancy, childbirth and on its respective direction that the mothers should follow could reduce perinatal mortality in high mortality regions of Ethiopia. In addition, strengthening maternal and child health services utilization and empowering mothers in making health care decisions should be emphasized.

\section{Appendix}

Comparisons of perinatal death between the final Analytic Sample with the Excluded Samples Due to Missing data

\begin{tabular}{llllll}
\hline Variable & Category & $\begin{array}{l}\text { Analytic } \\
\text { sample } \\
\text { Weighted } \\
\text { frequency } \\
\text { (\%) }\end{array}$ & $\begin{array}{l}\text { Missing } \\
\text { sample }\end{array}$ & $\begin{array}{l}\text { Weighted } \\
\text { frequency } \\
(\%)\end{array}$ & \\
\hline $\begin{array}{l}\text { Perinatal } \\
\text { death }\end{array}$ & Yes & 130(3.9) & 17(4.4) & 0.414 & 0.255 \\
\hline
\end{tabular}




\begin{abstract}
Abbreviations
ANC: Antenatal care; AOR: Adjusted odds ratio; Cl: Confidence intervals; CSA: Central Statistical Agency; DIC: Deviance information criterion; EAs: Enumeration areas; EDHS: Ethiopian Demographic and Health Survey; TT: Tetanus toxoid; ENAP: Every Newborn Action Plan.
\end{abstract}

\section{Acknowledgements}

We would like to thank the measure DHS program for providing the data set.

\section{Authors' contributions}

DG and ZA drafted the proposal, did the analysis, wrote the results, and organized the manuscript.BB Contributed on editing, analysis, and write-up of the result, and GF critically revised the manuscript for its scientific content. All authors read and approved the final manuscript.

\section{Funding}

The authors did not receive funding for this study.

\section{Availability of data and materials}

The data is available at the corresponding Author and may be provided upon request.

\section{Declarations}

\section{Ethics approval and consent to participate}

Since we have used a secondary data analysis that was publically available from the MEASURE DHS program, ethical approval and participant consent were not necessary. We had requested DHS Program and permission was allowed to download to use the data from https://www.dhsprogram.com/ there are no names of household addresses or individuals in the data.

\section{Consent for publication}

Not applicable.

\section{Competing interests}

The authors declare that they have no competing interests.

\section{Author details}

${ }^{1}$ Department of Midwifery, College of Health Science, Mizan-Tepi University, Mizan, Ethiopia. ${ }^{2}$ Department of Reproductive Health, School of Public Health, College of Health Science, Mizan-Tepi University, Mizan, Ethiopia.

Received: 4 August 2021 Accepted: 31 January 2022

Published online: 07 February 2022

\section{References}

1. Guevvera Y: World Health Organisation: Neonatal and perinatal mortality: country, regional and global estimates. WHO cebu: sun 2006.

2. Madaj B, Smith H, Mathai M, Roos N, van den Broek N. Developing global indicators for quality of maternal and newborn care. Bull World Health Organ. 2017;95(6):445-4521.

3. Hug L, Mishra A, Lee S, You D, Moran A, Strong KL, Cao B. A neglected tragedy The global burden of stillbirths: report of the UN inter-agency group for child mortality estimation, 2020. New York: United Nations Children's Fund; 2020

4. Estimation UNI-aGfCM: Levels \& Trends in Child Mortality: Report 2020, Estimates developed by the UN Inter-agency Group for Child Mortality Estimation. 2020

5. Hug L, Alexander M, You D, Alkema L. for Child Ul-aG: National, regional, and global levels and trends in neonatal mortality between 1990 and 2017, with scenario-based projections to 2030: a systematic analysis. Lancet Glob Health. 2019;7(6):e710-20.

6. Akombi BJ, Renzaho AM. Perinatal mortality in sub-Saharan Africa: a meta-analysis of demographic and health surveys. Ann Glob Health. 2019;85(1):106.

7. Tiruneh D, Assefa N, Mengiste B. Perinatal mortality and its determinants in Sub Saharan African countries: systematic review and meta-analysis. Maternal Health, Neonatology and Perinatology. 2021;7(1):1-17.
8. Organization WH. Every newborn: an action plan to end preventable deaths. 2014.

9. Wang H, Bhutta ZA, Coates MM, Coggeshall M, Dandona L, Diallo K, Franca EB, Fraser M, Fullman N, Gething PW. Global, regional, national, and selected subnational levels of stillbirths, neonatal, infant, and under-5 mortality, 1980-2015: a systematic analysis for the Global Burden of Disease Study 2015. The Lancet. 2016;388(10053):1725-74.

10. Csa I: Central Statistical Agency (CSA)[Ethiopia] and ICF. Ethiopia Demographic and Health Survey, Addis Ababa. In.; 2016.

11. Treading Economics, Ethiopia - Physicians https://tradingeconomics. com/ethiopia/physicians-per-1-000-people-wb-data.html> [Accessed September ,17 2021].

12. Jena BH, Biks GA, Gelaye KA, Gete YK. Magnitude and trend of perinatal mortality and its relationship with inter-pregnancy interval in Ethiopia: a systematic review and meta-analysis. BMC Pregnancy Childbirth. 2020;20(1):1-13.

13. Arach AAO, Tumwine JK, Nakasujja N, Ndeezi G, Kiguli J, Mukunya D, Odongkara B, Achora V, Tongun JB, Musaba MW. Perinatal death in Northern Uganda: incidence and risk factors in a community-based prospective cohort study. Glob Health Action. 2021;14(1):1859823.

14. Debelew GT. Magnitude and Determinants of Perinatal Mortality in Southwest Ethiopia. J Pregnancy. 2020;2020:7.

15. Seyoum E, Bekele A, Tsegaye AT, Birhanu S. Magnitude and Determinants of Adverse Perinatal Outcomes in Tefera Hailu Memorial Hospital, Sekota Town, Northern Ethiopia. Glob Pediatr Health. 2021:8:2333794X211015524.

16. Nwokoro UU, Dahiru T, Olorukooba A, Daam CK, Waziri HS, Adebowale A, Waziri NE, Nguku P. Determinants of perinatal mortality in public secondary health facilities, Abuja Municipal Area Council, Federal Capital Territory, Abuja, Nigeria. Pan Afr Med J. 2020;37:114.

17. Martins EF, Rezende EM. Almeida MCdM, Lana FCF: Perinatal mortality and socio-spatial inequalities. Rev Lat Am Enfermagem. 2013;21:1062-70.

18. Usynina AA, Grjibovski AM, Krettek A, Odland JØ, Kudryavtsev AV, Anda EE. Risk factors for perinatal mortality in Murmansk County, Russia: a registry-based study. Glob Health Action. 2017;10(1):1270536.

19. Geda A, Shemsu S, Debalke R. Determinants of Perinatal Mortality in Public Hospitals of Iluu Abbaa Boor Oromia Region, South West Ethiopia, 2019: Unmatched Case-Control Study. Research and Reports in Neonatology. 2021;11:57-66.

20. Hossain MB, Kanti Mistry S, Mohsin M, Rahaman Khan MH. Trends and determinants of perinatal mortality in Bangladesh. PloS one. 2019;14(8):e0221503.

21. Siddalingappa H, Nrayana Murthy M, Kulkarni P, Ashok N. Prevalence and factors influencing perinatal mortality in rural Mysore, India. Journal of clinical and diagnostic research: JCDR. 2013;7(12):2796.

22. Yirgu R, Molla M, Sibley L, Gebremariam A. Perinatal mortality magnitude, determinants and causes in west Gojam: population-based nested casecontrol study. PloS one. 2016;11(7):e0159390.

23. Roro EM, Sisay MM, Sibley LM. Determinants of perinatal mortality among cohorts of pregnant women in three districts of North Showa zone, Oromia Region, Ethiopia: Community based nested case control study. BMC Public Health. 2018;18(1):1-11.

24. Requejo J, Bryce J, Victora C, Deixel A, Barros A, Bhutta Z. Fulfilling the health agenda for women and children: the 2014 report. Geneva: United Nations Children's Fund and World Health Organization; 2014.

25. Andargie G, Berhane Y, Worku A, Kebede Y. Predictors of perinatal mortality in rural population of Northwest Ethiopia: a prospective longitudinal study. BMC Public Health. 2013;13(1):1-7.

26. Getiye $Y$, Fantahun M. Factors associated with perinatal mortality among public health deliveries in Addis Ababa, Ethiopia, an unmatched case control study. BMC Pregnancy Childbirth. 2017;17(1):1-7.

27. Tesfaye S, Gebru Z, Mamo M, Getahun F, Boti N. Determinants of Perinatal Mortality in Arba Minch General Hospital, Gamo Zone, Southern Ethiopia. Ethiopian Journal of Reproductive Health. 2019;11(4):7-7.

28. Al Kibria GM, Burrowes V, Choudhury A, Sharmeen A, Ghosh S, Mahmud A, Angela K. Determinants of early neonatal mortality in Afghanistan: an analysis of the Demographic and Health Survey 2015. Glob Health. 2018;14(1):1-12.

29. Conde-Agudelo A, Rosas-Bermudez A, Castaño F, Norton MH. Effects of birth spacing on maternal, perinatal, infant, and child health: a systematic review of causal mechanisms. Stud Fam Plann. 2012;43(2):93-114. 
30. Vogel JP, Habib NA, Souza JP, Gülmezoglu AM, Dowswell T, Carroli G, Baaqeel HS, Lumbiganon P, Piaggio G, Oladapo OT. Antenatal care packages with reduced visits and perinatal mortality: a secondary analysis of the WHO Antenatal Care Trial. Reprod Health. 2013;10(1):1-7.

31. Tafere TE, Afework MF, Yalew AW. Does antenatal care service quality influence essential newborn care (ENC) practices? In Bahir Dar City Administration, North West Ethiopia: a prospective follow up study. Ital J Pediatr. 2018;44(1):1-8.

32. Mondal D, Karmakar S, Banerjee A. Women's autonomy and utilization of maternal healthcare in India: Evidence from a recent national survey. PLoS One. 2020;15(12):e0243553.

33. Agha S, Carton TW. Determinants of institutional delivery in rural Jhang, Pakistan. International journal for equity in health. 2011;10(1):1-12.

34. Tiruneh FN, Chuang K-Y, Chuang Y-C. Women's autonomy and maternal healthcare service utilization in Ethiopia. BMC Health Serv Res. 2017;17(1):1-12.

35. Phukan D, Ranjan M, Dwivedi L. Impact of timing of breastfeeding initiation on neonatal mortality in India. Int Breastfeed J. 2018;13(1):1-10

36. Antehunegn G, Worku MG. Individual-and community-level determinants of neonatal mortality in the emerging regions of Ethiopia: a multilevel mixed-effect analysis. BMC Pregnancy Childbirth. 2021;21(1):1-11.

37. Fretts RC. Etiology and prevention of stillbirth. Am J Obstet Gynecol. 2005;193(6):1923-35.

\section{Publisher's Note}

Springer Nature remains neutral with regard to jurisdictional claims in published maps and institutional affiliations.

- fast, convenient online submission

- thorough peer review by experienced researchers in your field

- rapid publication on acceptance

- support for research data, including large and complex data types

- gold Open Access which fosters wider collaboration and increased citations

- maximum visibility for your research: over $100 \mathrm{M}$ website views per year

At BMC, research is always in progress.

Learn more biomedcentral.com/submissions 